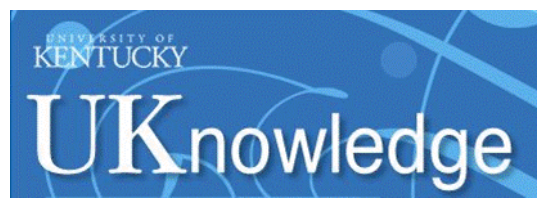

University of Kentucky

UKnowledge

Orthopaedic Surgery and Sports Medicine Faculty Publications

8-17-2016

\title{
Early Detection of Idiopathic Scoliosis in Adolescents
}

\author{
M. Timothry Hresko \\ Harvard University \\ Vishwas Talwalkar \\ University of Kentucky, vishwas.talwalkar1@uky.edu \\ Richard Schwend \\ University of Missouri - Kansas City
}

Follow this and additional works at: https://uknowledge.uky.edu/orthopaedicsurgery_facpub

Part of the Orthopedics Commons, Sports Sciences Commons, and the Surgery Commons

Right click to open a feedback form in a new tab to let us know how this document benefits you.

\section{Repository Citation}

Hresko, M. Timothry; Talwalkar, Vishwas; and Schwend, Richard, "Early Detection of Idiopathic Scoliosis in Adolescents" (2016). Orthopaedic Surgery and Sports Medicine Faculty Publications. 10.

https://uknowledge.uky.edu/orthopaedicsurgery_facpub/10

This Article is brought to you for free and open access by the Orthopaedic Surgery and Sports Medicine at UKnowledge. It has been accepted for inclusion in Orthopaedic Surgery and Sports Medicine Faculty Publications by an authorized administrator of UKnowledge. For more information, please contact UKnowledge@lsv.uky.edu. 


\section{Early Detection of Idiopathic Scoliosis in Adolescents}

\section{Digital Object Identifier (DOI)}

https://doi.org/10.2106/JBJS.16.00224

\section{Notes/Citation Information}

Published in The Journal of Bone \& Joint Surgery, v. 98, no. 16, e67, p. 1-4.

Copyright @ 2016 by The Journal of Bone and Joint Surgery, Incorporated

The copyright holder has granted the permission for posting the article here. 


\title{
ORTHOPAEDIC FORUM
}

\section{Early Detection of Idiopathic Scoliosis in Adolescents}

\author{
M. Timothy Hresko, MD, Vishwas Talwalkar, MD, and Richard Schwend, MD, on behalf of the AAOS, SRS, and POSNA
}

Peer review: This article was reviewed by the Editor-in-Chief and one Deputy Editor, and it underwent blinded review by two or more outside experts. The Deputy Editor reviewed each revision of the article, and it underwent a final review by the Editor-in-Chief prior to publication. Final corrections and clarifications occurred during one or more exchanges between the author(s) and copyeditors.

The early detection of idiopathic scoliosis has been advocated since the 1950 s and '60s, concurrent with the development in the modern era of ambulatory spinal orthoses to treat scoliosis in adolescents. This led to the development of screening programs for specific populations, as evidenced by school screening programs in the United States and public health systems in Europe and Asia. Over time, the value of population screening in terms of optimal health care and economics has been debated in the popular press, by the U.S. Preventive Services Task Force, and by professional societies. Recent studies on the effectiveness of bracing to prevent the progression of scoliosis, improved delineation of "at-risk populations," and refined orthotic management programs with emphasis on the use of compliance monitors have influenced the American Academy of Orthopaedic Surgeons (AAOS), the Scoliosis Research Society (SRS), the Pediatric Orthopaedic Society of North America (POSNA), and the American Academy of Pediatrics (AAP) to update their position on screening for scoliosis and has led to a joint position statement on the topic.

\section{AAOS, SRS, POSNA, and AAP Position Statement Screening for the Early Detection of Idiopathic Scoliosis in Adolescents}

This Statement was developed as an educational tool based on the opinion of the authors. It is not a product of a systematic review. Readers are encouraged to consider the information presented and reach their own conclusions.
The AAOS, SRS, POSNA, and AAP believe that there has been additional useful research in the early detection and management of adolescent idiopathic scoliosis (AIS) since the review performed by the U.S. Preventive Services Task Force (USPSTF) in 2004. This information should be available for use by patients, treating health care providers, and policy makers in assessing the relative risks and benefits of the early identification and management of AIS.

The AAOS, SRS, POSNA, and AAP believe that there are documented benefits of earlier detection and non-operative management of AIS, earlier identification of severe deformities that are surgically treated, and incorporation of screening of children for AIS by knowledgeable health care providers as a part of their care.

\section{Introduction}

Scoliosis is a three-dimensional spinal deformity characterized by lateral and rotational curvature of the spine. The most common form is idiopathic scoliosis, which usually becomes evident in the early adolescent years in approximately 3 percent of children under the age of 16 and has a genetic tendency, although the specifics of the genetic influence have not been completely determined. Curve progression is related to the age of the child and the magnitude of the deformity. The majority of children do not display progressive curves, although a subset of children with adolescent idiopathic scoliosis may exhibit rapid progression. Weinstein et al. reported in the New

Disclosure: One of the authors (M.T.H.) reports honoraria from DePuy Spine and the New England Journal of Medicine in relation to the submitted work. On the Disclosure of Potential Conflicts of Interest forms, which are provided with the online version of the article, one or more of the authors checked "yes" to indicate that the author had a relevant financial relationship in the biomedical arena outside the submitted work. 
The Journal of Bone \& Joint Surgery $\cdot$ JbJs.org Volume 98-A - Number 16 - August 17, 2016
Early Detection of Idiopathic Scoliosis in Adolescents

There have been several publications on screening for scoliosis since 2007, including a systematic review of the literature and large retrospective studies. In 2013, Labelle et al. published a consensus statement developed by an international task force of the SRS regarding screening for $\mathrm{AIS}^{10}$. The task force performed a systematic review of the literature through 2012 and used a modified Delphi process following the framework of the World Health Organization to reach consensus on the validity of a screening program. The panel reached consensus on the five domains studied, with four of the domains-technical efficacy and clinical, program, and treatment effectiveness-supportive of screening, but there was insufficient evidence to make a statement with respect to cost-effectiveness.

Screening examinations for spinal deformity vary in different locations, from a purely visual examination to a physical examination, scoliometer reading, and surface topographic measures during an annual health services examination. The finding of asymmetry during the clinical examination of chest and trunk is considered a proxy for spinal deformity. The forward-bend Adams test with the use of a scoliometer (a specialized inclinometer) was agreed upon by the SRS task force as an effective quantitative measure, with 5 to 7 degrees of deformity as a threshold for positive screening. The task force did not reach agreement on the need for topographic measurement. Since females reach puberty about two years before males and are afflicted with a magnitude of scoliosis requiring treatment three to four times more frequently than males, the task force recommended that screening be performed twice for females, once at age 10 and also at age 12 , in order to capture variation in maturity. Males could be screened once, at age 13 to 14 years.

The AAOS, SRS, POSNA, and AAP believe that screening examinations for spinal deformity should be part of the medical home preventive services visit for females at age 10 and 12 years, and for males, once, at age 13 or 14 years.

The clinical effectiveness of screening for the detection of curves greater than 20 degrees was supported in a large retrospective study by Luk et al. of 115,190 adolescents followed until the age of 19 years $^{11}$. In their study, 2.8 percent of adolescents were referred for a radiograph. At final follow-up, the positive predictive value for spinal curvature greater than 20 degrees was 43.8 percent and 9.8 percent for treatment. Sensitivity was near 90 percent for both diagnosis and treatment. Conversely, Yawn et al. reported on a population-based school screening program in Rochester, Minnesota ${ }^{6}$. In this retrospective cohort study, 4.1 percent (92 of 2,242) of the children screened positively and were referred for evaluation. The positive predictive value was low (0.05), and they concluded that roughly 450 children would need to be screened for every child who subsequently received treatment as a result of screening. The discrepancy in these studies points out the need for effective screening systems, as inappropriate false-positive screening may lead to unnecessary referrals and radiographs with higher population cost. Although well-done population screening may be an effective means to capture all children at risk, many communities may not have sufficient resources to carry out indicate that screening was not effective ${ }^{3}$. 
The Journal of Bone \& Joint Surgery $\cdot$ JbJs.org Volume 98-A - Number 16 - August 17, 2016
Early Detection of Idiopathic Scoliosis in Adolescents

point where surgery is indicated or, for severe curves, to be able to identify patients who would benefit from surgery before the deformity progresses to a degree that increases the risks associated with surgery.

Brace treatment for scoliosis has been the most prescribed non-operative method of treatment over the past 40 years. In recent years, refinements have been made in identifying which patients with idiopathic scoliosis may benefit most from this treatment ${ }^{18}$.

The two most common parameters used to assess the effectiveness of non-operative treatment of scoliosis have been defined as the ability to prevent curve progression to the point of surgery or to show a difference in the likelihood of curve progression of greater than 5 degrees by the time a patient has finished growth. Katz et al. demonstrated the efficacy of bracing in a non-controlled population, where 82 percent of patients who wore a brace for greater than 12 hours per day had less than 5 degrees of curve progression compared to only 31 percent of those who wore the brace for less than 7 hours per day ${ }^{19}$. An important feature of this study was that brace wear compliance was monitored by a temperature-sensitive data recorder imbedded in the spinal orthosis.

In 2013, the results of a multicenter National Institutes of Health (NIH)-funded, randomized clinical trial of the effectiveness of bracing to prevent progression of scoliosis were published $^{1}$. The Bracing in Adolescent Idiopathic Scoliosis Trial (BrAIST) included patients randomized to brace wear or no brace wear and a patient-preference cohort. The inclusion criteria were skeletal immaturity and moderate scoliosis of 20 to 40 degrees. The primary outcome was curve progression to 50 degrees or more (treatment failure) or reaching skeletal maturity without curve progression to 50 degrees (treatment success). The study was concluded prior to full enrollment by the NIH Data Safety and Monitoring Board due to the interim analysis that showed that braced patients had a significantly better rate of treatment success than non-braced patients. In the randomly assigned group, 75 percent of braced patients versus 42 percent of observational patients successfully reached skeletal maturity with a curve magnitude of less than 50 degrees (surgical range). This was a 56 percent reduction in relative risk of progression to a surgical level of scoliosis. The success rate of bracing was highly correlated to the number of hours of brace wear, based on a temperature data recorder for compliance monitoring. The number of patients needed to treat (NNT) in order to prevent one surgery was three. No difference was found in patient-reported quality of life or adverse effects in the braced or observational patients. An independent study by Sanders et al. supported the results of BrAIST with a similar NNT of three $e^{20}$.

Other means for non-operative treatment of scoliosis have also been studied. Scoliosis-specific exercises used to supplement brace wear or prevent progression in mild curves have been reported. A randomized clinical trial of patients with mild scoliosis of 10 to 20 degrees has shown that scoliosis-specific exercises may prevent progression to the level of deformity that would result in brace treatment ${ }^{21}$.

\section{Treatment of Those Detected in Scoliosis Screening}

Effective treatment of patients referred from scoliosis screening should be able to reduce the risk of a curve progressing to a

these programs. In all communities, primary care providers
serve as an important source for screening. Education of primary care providers in the clinical examination for early detecgraph but are not found to have scoliosis ${ }^{8}$. All studies of screenprograms show that there is a significant rate of false spinal imaging. Current techniques of shielding, patient pos phy, and ner low-dose imaing systems using slit scan. have significantly reduced the radiation exposure. Luo et al. d that current imaging techniques have reduced radiatio in patients reported by Doody et al. in the U.S. scoliosis cohort The AAOS, SRS, POSNA, and AAP believe that the principles of ALARA (as low as reasonably achievable) should be applied in the diagnostic imaging of children to decrease radiation exposure from spinal imaging for $\mathrm{AIS}^{17}$. 
The Journal of Bone \& Joint Surgery $\cdot$ JbJs.org Volume 98-A • Number $16 \cdot$ August 17, 2016
Early Detection of Idiopathic Scoliosis in Adolescents

scoliosis can be found at the following: AAOS.org; SRS.org; POSNA.org; and healthychildren.org.

NoTE: The authors thank and acknowledge the board of directors of AAOS, SRS, POSNA, and AAP, who have edited and approved this joint position statement.

may reduce the number of patients progressing to a surgical level. To be effective, these treatments need to be applied to smaller curves prior to skeletal maturity. This places emphasis on the need for earlier detection of scoliosis. Early detection by screening programs that identify adolescents at risk for progression will offer patients and families the opportunity to seek effective, non-operative treatments. The patient preference of non-operative brace treatment rather than observation was noted in the patient preference arm of BrAIST, where there was a 2:1 ratio for selection of bracing over observation. Nonoperative therapies are most effective for curves of lesser magnitudes, thus supporting the value of early detection.

The AAOS, SRS, POSNA, and AAP believe that recent high-quality studies demonstrate that non-operative interventions such as bracing and scoliosis-specific exercises can decrease the likelihood of curve progression to the point of requiring surgical treatment.

Educational resources that provide more specific instruction and guidelines for conducting screening examinations for
M. Timothy Hresko, $\mathrm{MD}^{1}$

Vishwas Talwalkar, $\mathrm{MD}^{2}$

Richard Schwend, $\mathrm{MD}^{3}$

${ }^{1}$ Departments of Orthopaedic Surgery, Harvard Medical School and

${ }^{2}$ Departments of Orthopaedic Surgery, University of Kentucky and Shriners Hospitals for Children, Lexington, Kentucky

${ }^{3}$ University of Missouri-Kansas City School of Medicine and University of Kansas Medical Center, Children's Mercy Hospital, Kansas City, Missouri

E-mail address for V. Talwalkar: vtalwalkar@shrinenet.org

E-mail address for R. Schwend: rmschwend@cmh.edu Boston Children's Hospital, Boston, Massachusetts

E-mail address for M.T. Hresko: timothy.hresko@childrens.harvard.edu

\section{References}

1. Weinstein SL, Dolan LA, Wright JG, Dobbs MB. Effects of bracing in adolescents with idiopathic scoliosis. N Engl J Med. 2013 Oct 17;369(16):1512-21. Epub 2013 Sep 19.

2. Richards BS, Vitale MG. Screening for idiopathic scoliosis in adolescents. An information statement. J Bone Joint Surg Am. 2008 Jan;90(1):195-8.

3. U.S. Preventive Services Task Force. Final recommendation statement: idiopathic scoliosis in adolescents: screening, June 2004. http://www. uspreventiveservicestaskforce.org/Page/Document/Recommendation StatementFinal/idiopathic-scoliosis-in-adolescents-screening. Accessed 2015 Aug 30.

4. Ashworth MA, Hancock JA, Ashworth L, Tessier KA. Scoliosis screening. An approach to cost/benefit analysis. Spine (Phila Pa 1976). 1988 Oct;13(10):1187-8.

5. Montgomery F, Willner S. Screening for idiopathic scoliosis. Comparison of 90 cases shows less surgery by early diagnosis. Acta Orthop Scand. 1993 Aug;64(4):456-8.

6. Yawn BP, Yawn RA, Hodge D, Kurland M, Shaughnessy WJ, Ilstrup D, Jacobsen SJ. A population-based study of school scoliosis screening. JAMA. 1999 Oct 20;282 (15):1427-32.

7. Yawn BP, Yawn RA. The estimated cost of school scoliosis screening. Spine (Phila Pa 1976). 2000 Sep 15;25(18):2387-91.

8. Morais T, Bernier M, Turcotte F. Age- and sex-specific prevalence of scoliosis and the value of school screening programs. Am J Public Health. 1985 Dec;75(12):1377-80. 9. Agency for Healthcare Research and Quality (US). US Preventive Services Task Force guides to clinical preventive services. Rockville, MD: Office of Disease Prevention and Health Promotion, 1996.

10. Labelle H, Richards SB, De Kleuver M, Grivas TB, Luk KD, Wong HK, Thometz J, Beauséjour M, Turgeon I, Fong DY. Screening for adolescent idiopathic scoliosis: an information statement by the Scoliosis Research Society international task force. Scoliosis. 2013;8:17. Epub 2013 Oct 31.

11. Luk KD, Lee CF, Cheung KM, Cheng JC, Ng BK, Lam TP, Mak KH, Yip PS, Fong DY. Clinical effectiveness of school screening for adolescent idiopathic scoliosis: a large population-based retrospective cohort study. Spine (Phila Pa 1976). 2010 Aug 1;35(17):1607-14.
12. Vernacchio L, Trudell EK, Hresko MT, Karlin LI, Risko W. A quality improvement program to reduce unnecessary referrals for adolescent scoliosis. Pediatrics. 2013 Mar;131(3):e912-20. Epub 2013 Feb 18.

13. Lee CF, Fong DY, Cheung KM, Cheng JC, Ng BK, Lam TP, Mak KH, Yip PS, Luk KD. Costs of school scoliosis screening: a large, population-based study. Spine (Phila Pa 1976). 2010 Dec 15;35(26):2266-72.

14. Ramo BA, Richards BS. Repeat surgical interventions following "definitive" instrumentation and fusion for idiopathic scoliosis: five-year update on a previously published cohort. Spine (Phila Pa 1976). 2012 Jun 15;37(14):1211-7.

15. Campos $M$, Dolan $L$, Weinstein $S$. Unanticipated revision surgery in adolescent idiopathic scoliosis. Spine (Phila Pa 1976). 2012 May 20;37(12):1048-53.

16. Luo TD, Stans AA, Schueler BA, Larson N. Cumulative radiation exposure with EOS imaging compared with standard spine radiographs. J Spine Deformity. 2015;3:144-50.

17. The ALARA. The ALARA (as low as reasonably achievable) concept in pediatric CT intelligent dose reduction. Multidisciplinary conference organized by the Society of Pediatric Radiology. August 18-19, 2001. Pediatr Radiol. 2002 Apr;32(4):217313. Epub 2002 Mar 6.

18. Richards BS, Bernstein RM, D'Amato CR, Thompson GH. Standardization of criteria for adolescent idiopathic scoliosis brace studies: SRS Committee on Bracing and Nonoperative Management. Spine (Phila Pa 1976). 2005 Sep 15;30(18):206875; discussion 2076-7.

19. Katz DE, Herring JA, Browne RH, Kelly DM, Birch JG. Brace wear control of curve progression in adolescent idiopathic scoliosis. J Bone Joint Surg Am. 2010 Jun;92 (6):1343-52.

20. Sanders JO, Newton PO, Browne RH, Katz DE, Birch JG, Herring JA. Bracing for idiopathic scoliosis: how many patients require treatment to prevent one surgery? J Bone Joint Surg Am. 2014 Apr 16;96(8):649-53.

21. Monticone M, Ambrosini E, Cazzaniga D, Rocca B, Ferrante S. Active selfcorrection and task-oriented exercises reduce spinal deformity and improve quality of life in subjects with mild adolescent idiopathic scoliosis. Results of a randomised controlled trial. Eur Spine J. 2014 Jun;23(6):1204-14. Epub 2014 Feb 28. 